\title{
Implementasi Algoritma Greedy untuk Menyelesaikan Travelling Salesman Problem di Distributor PT. Z
}

\section{The Implementation of Greedy Algorithm for Solving Travelling Salesman Problem in a Distribution Company}

\author{
Muhammad Zakaria Usman, Teguh Oktiarso \\ Program Studi Teknik Industri, Universitas Ma Chung, Malang \\ E-mail: muhammadzakaria2905@gmail.com
}

\begin{abstract}
Abstrak
Departemen logistik merupakan departemen yang memegang peran penting dalam perusahaan karena bertugas untuk menyalurkan barang ke konsumen. PT. Z merupakan perusahaan distributor produk-produk obat dan barang kebutuhan sehari-hari menghadapi permasalahan rute distribusi dalam menyalurkan produk obat dan barang kebutuhan sehari hari. Penyelesaian masalah yang dihadapi oleh PT. X adalah menggunakan Travelling Salesman Problem dengan pendekatan algoritma Greedy untuk mendapatkan rute distribusi terpendek.. Hasil dari rancangan rute distribusi baru menghasilkan bahwa rayon Tangerang Kota memiliki total waktu pengiriman 6 jam 44 menit, rayon Bumi Serpong Damai 6 jam 38 menit, rayon Ciledug 5 jam 21 menit, rayon Pamulang, Bintaro, Ciputat 5 jam 01 menit, rayon Curug, Cikupa, Balaraja 5 jam 41 menit, dan rayon Seluruh Rumah Sakit 6 jam 50 menit. Hasil dari perancangan rute baru juga menyebabkan perubahan terhadap biaya distribusi yaitu perubahan pada biaya penggunaan bahan bakar minyak yang lebih kecil dari sebelumnya.

Kata kunci: rute distribusi, algoritma Greedy, Travelling Salesman Problem
\end{abstract}

\begin{abstract}
A logistic department is the most important part in a company becau se its service, distributing product to customer. PT. $Z$ is a pharmaceutical and daily product distributor which have distribution routing problem in Tangerang Area. The Travelling Salesman Problem with Greedy Algorithm is used to solve the distribution routing problem. The aim of using Travelling Salesman Problem with Greedy Algorithm is to find the shortest route in distributing goods in Tangerang Area. The result of the research is new distribution route which is shorter than before. The result is the shorten time for each distribution routes which are for Tangerang Kota Area became 6 hours 44 minutes, Bumi Serpong Damai area became 6 hours and 38 minutes, Ciledug area became 5 hours and 21 minutes, Pamulang, Bintaro and Ciputat area became 5 hours and 01 minutes, Curug, Cikupa, Balaraja area became 5 hours and 41 minutes and Hospitals in Tangerang became 6 hours and 50 minutes. The result also reduce distribution cost especially in fuel cost.
\end{abstract}

Keywords: distribution routing, greedy algorithm, Travelling Salesman Problem

\section{Pendahuluan}

Departemen logistik merupakan salah satu departemen yang memegang peran penting dalam suatu perusahaan. Salah satu perannya adalah menyalurkan barang kepada konsumen. Dalam menyalurkan suatu barang, suatu perusahaan terkadang memiliki suatu permasalahan yaitu menentukan jarak atau rute terpendek dalam mendistribusikan barang untuk meminimalkan biaya pengiriman.

Salah satu perusahaan yang memiliki permasalahan dengan menentukan jarak atau rute terpendek adalah PT. Z. PT. Z merupakan salah satu perusahaan distributor produk berupa obat dan barang kebutuhan sehari-hari yang diproduksi oleh berbagai perusahaan. Jenis produk yang didistribusikan PT. Z sekitar 2.362 item. Produk tersebut terbagi dua yaitu produk pharma dan produk konsumer. Produk pharma berupa obat-obatan yang harus memiliki resep dokter sebesar 1.216 item, sedangkan produk konsumer berupa kebutuhan sehari-hari seperti susu, minuman ringan, dan lain sebagainya sebesar 1.146 item. Beberapa contoh produk yang didistribusikan berupa obat yaitu 
dalam bentuk botol sirup, tablet, dan kapsul dan untuk konsumer berupa susu, minuman, dan lain sebagainya.

PT. Z terletak di daerah Tangerang dimana PT. Z bertugas untuk melayani pengiriman produk ke apotek, toko retail, rumah sakit di wilayah Kota Tangerang dan sekitarnya. Pengiriman barang terbagi menjadi dua yaitu pengiriman luar kota dan dalam kota. Pengiriman luar kota terdiri dari Cilegon, Serang, Pandeglang, dan Lebak (Rangkas) sedangkan untuk dalam kota adalah Tangerang, Tangerang Selatam, Pamulang, Kabupaten Tangerang. Pengiriman barang dilakukan pada hari Senin hingga Sabtu. Jam pengiriman terbagi menjadi dua yaitu, pukul 10.00 hingga selesai dan pukul 13.00 hingga selesai. Jadwal pengiriman barang untuk setiap tempat sudah dimiliki, seperti Outlet X dikirim pada hari senin dan sebagainya. Pengiriman luar kota terdapat 1.012 outlet yang terbagi menjadi 4 wilayah sedangkan pengiriman dalam kota terdapat 2.257 outlet. Berikut merupakan jumlah outlet yang dilayani PT. Z pada pengiriman da lam kota.

Tabel 1. Daerah Pengiriman Dalam Kota beserta Jumlah Outlet Pharma dan Consumer

\begin{tabular}{|c|c|c|}
\hline No. & Nama Daerah & Jumlah Outlet \\
\hline 1 & Tangerang & 1851 \\
\hline 2 & Tangerang Selatan & 355 \\
\hline 3 & Pamulang & 13 \\
\hline 4 & Kabupaten Tangerang & 38 \\
\hline
\end{tabular}

PT. Z menyediakan empat kendaraan untuk melakukan pengiriman barang luar kota dengan melakukan kerjasama dengan pihak ketiga dan enam belas kendaraan untuk pengiriman barang dalam kota dengan pembagian tujuh kendaraan untuk pharma dan sembilan untuk konsumer. Pengiriman barang dalam kota untuk pharma terbagi menjadi enam rayon yaitu Tangerang Kota, Bumi Serpong Damai, Ciledug, Pamulang, B intaro, Ciputat, Curug, Cikupa, Balaraja, dan seluruh rumah sakit. Seluruh rumah sakit merupakan satu rayon sendiri dimana pengiriman khusus dilakukan untuk rumah sakit walaupun rumah sakit tersebut berada dirayon lainnya. Berikut adalah jumlah outlet untuk masing-masing pengiriman barang pharma.

Tabel 2. Daerah Pengiriman Dalam Kota beserta Jumlah Outlet Pharma

\begin{tabular}{|c|c|c|}
\hline No. & Nama Daerah & Jumlah Outlet \\
\hline 1 & Tangerang Kota & 84 \\
\hline 2 & Bumi Serpong Damai & 93 \\
\hline 3 & Ciledug & 61 \\
\hline 4 & Pamulang, Bintaro, Ciputat & 48 \\
\hline 5 & Curug, Cikupa, Balaraja & 44 \\
\hline 6 & Seluruh Rumah Sakit & 38 \\
\hline
\end{tabular}

Pengiriman barang dilakukan berdasarkan jumlah surat jalan, pada surat jalan terdapat jumlah outlet yang akan dikirim sehingga tiap kurir memiliki jumlah outlet yang berbeda-beda. Jumlah outlet setiap hari pengiriman rata-rata 250 outlet per hari untuk pharma dan consumer, sedangkan untuk barang milik pharma sendiri rata-rata pengiriman 108 outlet per hari. Outlet yang tidak melakukan order selama enam bulan maka dinyatakan outlet tidak aktif. Sistem distribusi yang diterapkan PT. Z merupakan sistem pendistribusian dimana barang yang di order pada hari itu harus dikirim hari itu juga (one day service). Setiap harinya jumlah outlet tidak selalu sama, proses pengiriman barang pada PT. Z tidak melakukan perhitungan terhadap outlet mana yang didatangi lebih dahulu, sehingga waktu pengiriman tidak optimal serta barang yang akan dikirim tidak teratur tempatnya yang menyebabkan kesulitan pada saat ingin menurunkan barang yang akan dikirim.

Oleh karena itu perlu dilakukan pengoptimalan rute baru dengan menggunakan algoritma Greedy. Diharapkan dengan adanya pembuatan rute dengan menggunakan algoritma Greedy dapat 
membantu perusahaan dalam menentukan rute terpendek sehingga dapat meminimalkan biaya pengiriman dan meminimalkan total waktu perjalanan distribusi.

\section{Tinjauan Pustaka}

2.1 Sis tem Distribusi

Sistem distribusi adalah kegiatan pemasaran untuk menyalurkan produk atau jasa dari prosuden kepada konsumen yang disesuaikan terhadap jenis, jumlah, harga, dan tempat yang diperlukan (Budiarto, 1993). Distribusi dilakukan guna mempermudah para konsumen untuk memperoleh suatu produk. Hal tersebut dapat mempermudah para konsumen dalam memperoleh suatu produk apabila proses pendistribusiannya efektif. Adapun faktor-faktor yang harus dipersiapkan dalam suatu sistem distribusi (Nasution, 2006) adalah gudang penyimpanan, pabrik pemasok produk, konsumen yang dilayani, alat transportasi, rute transportasi, dan sistem pengenda lian persediaan.

\subsection{Algoritma}

Algoritma berasal dari nama belakang seorang tokoh matematikawan Persia yang bernama Muhammad ibn Musa al-Khuwarizmi. Algoritma merupakan suatu metode yang digunakan untuk menyelesaikan permasalahan-permasalahan tertentu dengan melakukan urutan terhadap langkahlangkah apa saja yang dilakukan dengan cara sistematis (Zarlis dan Handrizal, 2008).

Dalam pemilihan algoritma terdapat tiga hal yang harus dipertimbangkan, yaitu algoritma haruslah benar, mengetahui hasil yang dicapai oleh algoritma tersebut, dan mengetahui seberapa efesienkah algoritma tersebut. Berikut adalah penjelasan lebih rincinya (Zarlis dan Handrizal, 2008):

1. Algoritma memliki awal dan akhir proses sehingga algoritma harus berhenti bekerja apabila telah mengerjakan sejumlah langkah yang terbatas.

2. Setiap langkah harus dije laskan secara tepat dan jelas.

3. Algoritma memiliki masukan (input) yang berupa besaran sebelum algoritma bekerja.

4. Algoritma memliki keluaran (output) yang merupakan hasil pelaksanaan algoritma dari masukan yang sudah diberikan di awal proses.

5. Algoritma harus efektif, yaitu langkah-langkah harus sederhana sehingga dapat dikerjakan dalam waktu singkat.

\subsection{Travelling Salesman Problem}

William Rowan Hamilton dan Thomas Penyngton merupakan orang yang pertama kali menemukan travelling salesman problem (Mindaputra, 2009). Permainan Icosian Hamilton merupakan asal mula ditemukannya TSP. Dalam permainan tersebut diminta untuk menyelesaikan perjalanan dari 20 titik berbeda yang melewati jalur-jalur tertentu.

TSP merupakan permasalahan yang dialami salesman dalam mencari rute terpendek yang dapat dilalui dengan mengunjungi beberapa tempat tanpa harus mengulang untuk melewati tempat yang telah dilewati artinya salesman tidak melewati tempat atau titik yang sama lebih dari satu kali tetapi salesman dapat menyelesaikannya sampai kembali ke tempat atau titik awal (Applegate dkk., 2016).

Dalam menyelesaikan permasalahan TSP terdapat beberapa algoritma yang digunakan, salah satunya adalah algoritma Greedy. Algoritma Greedy merupakan suatu metode yang digunakan untuk memecahkan permasalahan optimasi dimana setiap langkah akan memilh kota atau tempat yang belum dikunjungi, kota atau tempat yang belum dikunjungi dipilih berdasarkan jarak kota atau tempat mana yang terdekat dari kota atau tempat sebelumnya (Wijayanti, 2013). Berikut adalah cara perhitungan dengan menggunakan algoritma Greedy:

1. Tentukan kota atau tempat awal dimula inya perjalanan.

2. Kemudian kota awal menuju kota selanjutnya dimana kota selanjutnya tersebut berada paling dekat dari kota awal.

3. Kemudian lanjut ke kota berikutnya yang terdekat hingga kota tujuan selesai.

4. Selanjutnya balik ke kota awal dan jumlahkan seluruh jarak tersebut. 
Berdasarkan definisi diatas, maka dapat disimpulkan bahwa persyaratan dalam menye lesaikan TSP yaitu (Wijayanti, 2013):

1. Tidak dapat melewati setiap kota lebih ataupun kurang dari satu kali

2. Setiap kota harus dapat dikunjungi dan diselesaikan dalam satu kali perja lanan atau rute

3. Salesman harus kembali ke titik atau kota awal untuk mengakhiri perja lanan

Parameter yang digunakan dalam TSP adalah $d$ sebagai jarak dari kota $i$ ke kota $j$. Berikut merupakan model persamaan TSP (Taha, 2007):

$$
x_{i j}= \begin{cases}1, j \text { jika kota } \mathrm{j} \text { dicapai dari kota } \mathrm{i} \\ 0, \quad \text { jika sebaliknya }\end{cases}
$$

Fungsi tujuan

$$
\text { : Min } z=\sum_{i=1}^{n} \sum_{j=1}^{n} d_{i j} x_{i j}, d_{i j}=\infty \text { untuk semua } i=j
$$

$\sum_{n=1}^{n} x_{i j}=1$

$$
i=1, \ldots, \mathrm{n}
$$

$\sum_{n=1}^{n} x_{i j}=1$

$j=1, \ldots, \mathrm{n}$

$x_{i j}=(0,1)$

\subsection{Penelitian Terdahulu}

Penelitian mengenai penggunaan aplikasi untuk menyelesaikan permasalahan travelling salesman problem telah dilakukan oleh beberapa orang. Penelitian pertama dilakukan oleh Kusrini dan Istiyanto (2007). Pada penelitian tersebut digunakan penerapan algoritma Cheaspest Insertion Heuristic dan Basis Data untuk travelling salesman problem. Peneliti menggunakan Borland Delphi 6 dan Interbase 6 sebagai tools dalam implementasi TSP. Pada penelitian tersebut, peneliti berhasil diimplementasikan algoritma $\mathrm{CIH}$ dan basis data. Tetapi pada penelitian tersebut, implementasi algoritma belum mampu menyelesaikan masalah pencarian rute jika ada dua kota yang mimiliki bobot yang berbeda dengan melihat arahnya dan jika ada dua buah kota yang tidak terhubung.

Penelitian lain dengan menggunakan aplikasi untuk menyelesaikan permasalahan travelling salesman problem telah dilakukan oleh Andri, dkk (2013). Pada penelitian tersebut digunakan aplikasi Travelling Salesman Problem dengan metode Artificial Bee Colony. Pada penelitian tersebut, peneliti menggunakan bahasa pemrograman Visual Basic 2008. Dengan menggunakan aplikasi dan metode Artificial Bee Colony, waktu proses jauh lebih cepat dibadingkan dengan perhitungan manual. 
JOURNAL OF INTEGRATED S YSTEM VOL 1. NO.2, DESEMB ER 2018: 216-229

\section{Metode Penelitian}

Langkah-langkah penelitian yang dilakukan dapat dilihat pada diagram alir berikut:

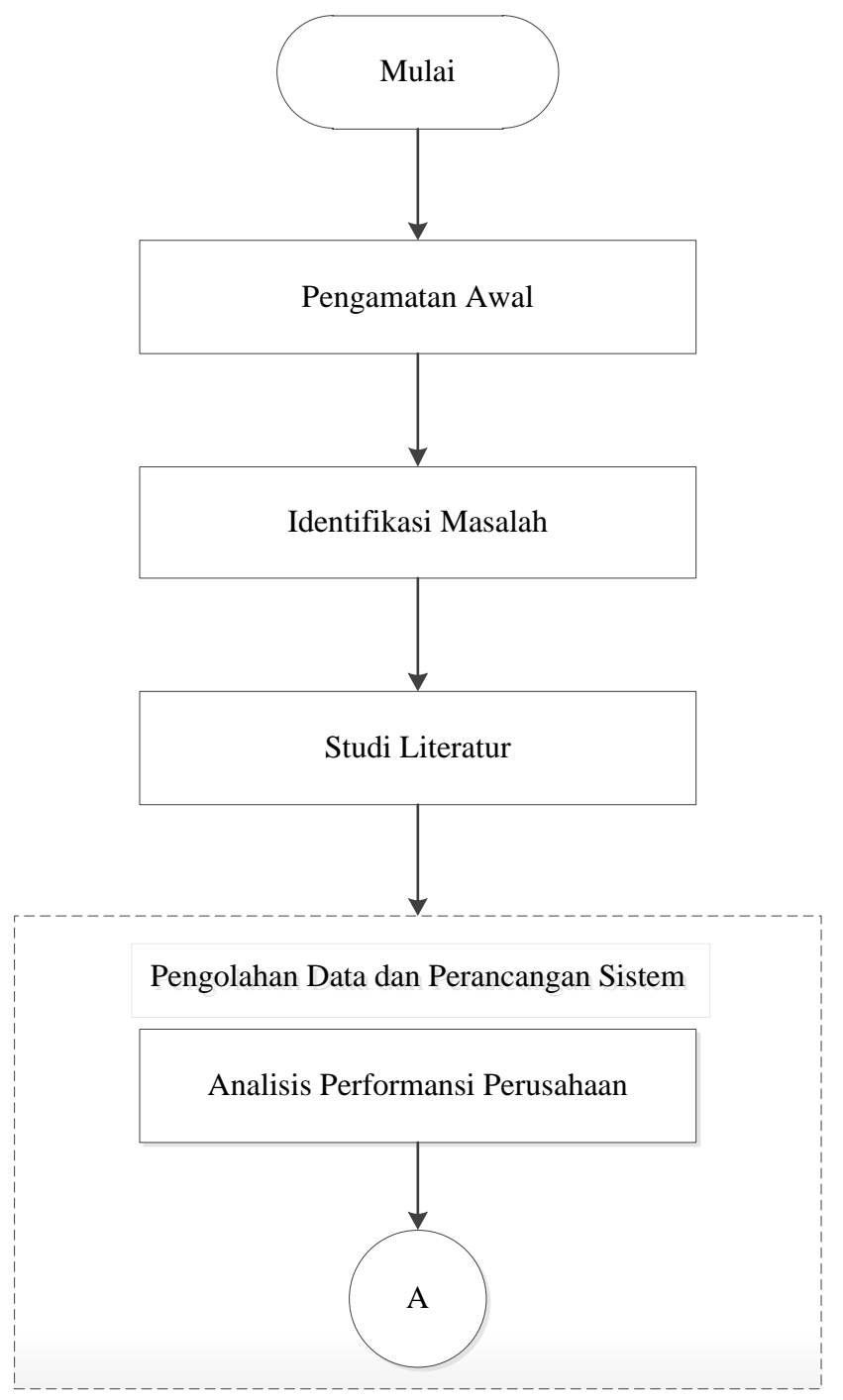

Gambar 1. Diagram Alir Penelitian 


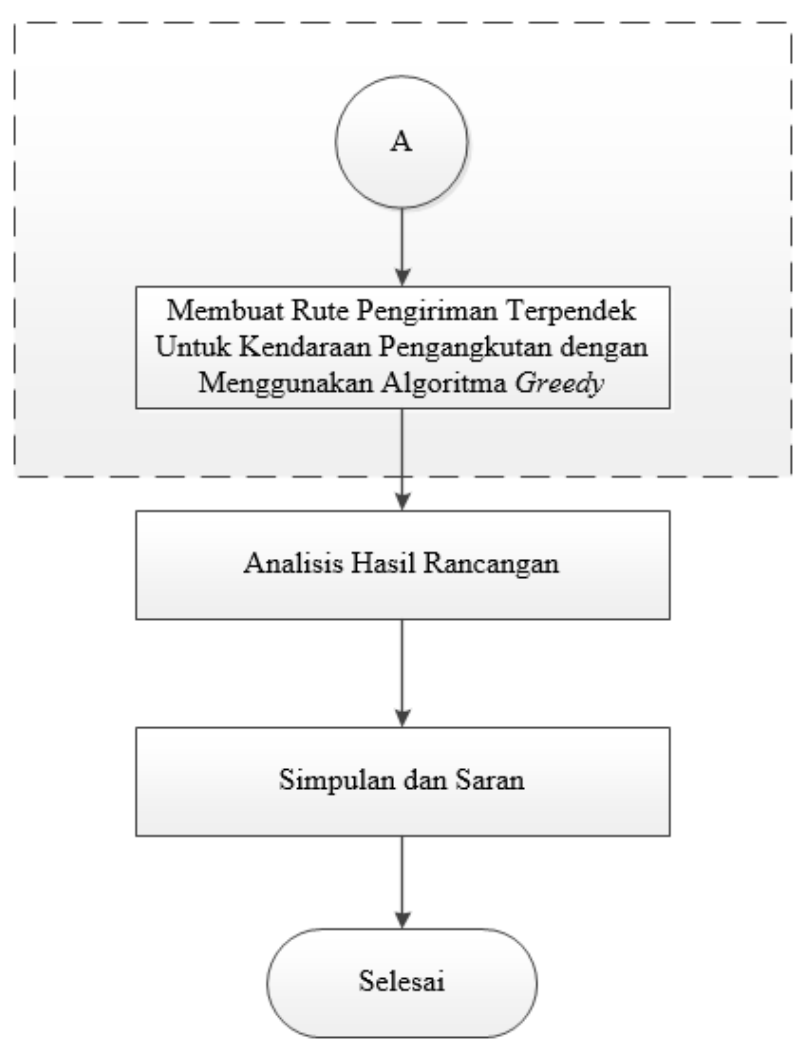

Gambar 1. Diagram Alir Penelitian (Lanjutan)

Pengamatan awal bertujuan untuk melihat kondisi atau situsi awal dari obyek penelitian. Obyek penelitian adalah proses distribusi pengiriman dalam kota yang dilakukan PT. Z yang merupakan distributor produk-produk yang di produksi oleh beberapa perusahaan. Pendistribusian dilakukan dengan menggunakan enambelas buah mobil. Pendistribusian untuk barang konsumer menggunakan sembilan buah mobil, sedangkan untuk barang pharma menggunakan tujuh buah mobil. Pada pendistribusian barang pharma terdapat dua jenis mobil yaitu Grand Max dan L. 300. Untuk besar muatan mobil berjenis Grand Max dapat menampung 267 karton, sedangkan untuk L. 300 dapat menampung 156 karton. Rute distribusi untuk rayon Tangerang Kota, Bumi Serpong Damai, Ciledug, Pamulang, B intaro, Ciputat, Curug, Cikupa, Balaraja, dan seluruh rumah sakit yang diterapkan masih belum optimal. Pada pengamatan awal didapatkan bahwa waktu pengiriman terhadap rute distribusi seluruh rayon pengiriman belum optimal atau melebihi dari jadwal pengiriman yang telah ditentukan. Dengan rute distribusi untuk seluruh rayon pengiriman masih belum optimal, tentunya hal itu menyebabkan biaya distribusi yang belum optimal atau efisien juga.

Identifikasi masalah dilakukan untuk mengetahui permasalahan yang terdapat pada obyek penelitian. Berdasarkan hasil dari pengamatan awal, diketahui bahwa proses distribusi PT. Z pada pemilihan rute distribusi untuk rayon Tangerang Kota, Bumi Serpong Damai, Ciledug, Pamulang, Bintaro, Ciputat, Curug, Cikupa, Balaraja, dan seluruh rumah sakit belum optimal. Oleh karena itu didapatkan adanya identifikasi masalah, yaitu perlu adanya perbaikan terhadap rute distribusi pada setiap kendaraan pengangkutan untuk rayon Tangerang Kota, Bumi Serpong Damai, Ciledug, Pamulang, Bintaro, Ciputat, Curug, Cikupa, Balaraja, dan seluruh rumah sakit.

Studi literatur dilakukan untuk mengetahui metode atau penyelesaian yang tepat untuk menyelesaikan masalah yang didapat. Hasil dari studi literatur, didapatkan bahwa metode yang sesuai untuk menyelesaikan masalah rute pendistribusian pada setiap kendaraan pengangkutan untuk rayon Tangerang Kota, Bumi Serpong Damai, Ciledug, Pamulang, Bintaro, Ciputat, Curug, Cikupa, Balaraja, dan seluruh rumah sakit adalah dengan menggunakan algoritma Greedy. 
Pengumpulan data dilakukan untuk mendapatkan data yang lengkap dan valid. Data tersebut digunakan sebagai dasar kerja penelitian untuk menyelesaikan masalah rute pendistribusian. Metode pengumpulan data yang dilakukan adalah wawancara, pengamatan langsung dan dokumentasi. Berikut adalah keterangan dari metode pengumpulan data:

1. Wawancara

Wawancara dilakukan dengan metode in-depth interview kepada kepala ekspedisi dan kepala gudang di PT. Z. Sebelum melalukan wawancara, dipersiapkan terlebih dahulu bahan pertanyaan yang terkait dengan penelitian yang dilakukan. Hasil dari wawancara yang didapatkan mengenai gambaran distribusi yang diterapkan, jumlah rayon serta konsumen, jumlah konsumen yang melakukan permintaan setiap harinya, performansi supir dan kendala yang dihadapi, serta jenis barang yang setiap harinya diminta oleh konsumen.

2. Pengamatan langsung

Pengamatan langsung dilakukan untuk mengetahui proses distribusi yang terdapat pada PT. Z. Metode yang digunakan adalah dengan metode observasi. Pengamatan dilakukan dengan cara ikut me lakukan pengiriman guna mengetahui waktu perjalanan ke setiap outlet serta mengetahui hal apa saja yang menghambat proses distribusi.

3. Dokumentasi

Dokumentasi dilakukan untuk mengetahui data mengenai PT. Z yang mendukung pengerjaan laporan. Data dokumentasi yang diambil antara lain data konsumen dan biaya distribusi.

Data yang didapatkan merupakan data primer dan data sekunder. Data primer merupakan data yang diperoleh berdasarkan pengamatan langsung. Data primer yang didapatkan seperti waktu perjalanan ke setiap outlet, waktu pelayanan setiap outlet dan jumlah permintaan setiap outlet. Data sekunder merupakan data yang diperoleh dari PT. Z. Data sekunder yang didapatkan adalah data konsumen seluruh rayon pengiriman yaitu Tangerang Kota, Bumi Serpong Damai, Ciledug, Pamulang, Bintaro, Ciputat, Curug, Cikupa, Balaraja, dan seluruh rumah sakit, serta biaya distribusi barang yang dikeluarkan oleh PT. Z untuk setiap kendaraan pengiriman.

Data-data yang telah didapatkan kemudian diolah sehingga dapat dilakukan pembuatan rute baru. Berikut adalah tahapan yang dilakukan dalam mengolah data:

1. Mengidentifikasi performansi awal perusahaan. Performansi awal dilakukan dengan menghitung total waktu perjalanan setiap kendaraan dalam satu hari sesuai dengan sitem distribusi yang diterapkan perusahaan dan untuk mengetahui total biaya setiap kendaraan beserta apa saja yang dikeluarkan untuk setiap pengiriman barang.

2. Pembuatan rute distribusi baru dimana setiap kendaraan pengangkutan yang melayani rayon Tangerang Kota, Bumi Serpofng Damai, Ciledug, Pamulang, Bintaro, Ciputat, Curug, Cikupa, Balaraja, dan seluruh rumah sakit dapat memiliki waktu tempuh yang lebih optimal dengan menggunakan algoritma Greedy. Pembuatan rute baru dilakukan untuk mendapatkan rute terpendek dari setiap kendaraan dengan cara mengambil waktu tempuh terkecil untuk ke outlet tujuan selanjutnya dan mengurangi biaya distribusi yang dikeluarkan oleh PT. Z agar menjadi lebih efisien.

Analisis dilakukan untuk mengetahui atau melihat perbedaan yang dihasilkan sebelum dan setelah adanya pembuatan rute baru untuk setiap kendaraan pengangkutan di PT. Z yang melayani rayon Tangerang Kota, Bumi Serpong Damai, Ciledug, Pamulang, Bintaro, Ciputat, Curug, Cikupa, Balaraja, dan seluruh rumah sakit. Analis is dilakukan dengan melihat total waktu yang ditempuh kendaraan dalam satu hari serta melihat perbedaan biaya yang dikeluarkan sebelum dan setelah adanya pembuatan rute baru serta melihat perbedaan sebelum dan setelah adanya pembuatan rute baru terhadap biaya distribusi yang dikeluarkan oleh PT. Z.

Simpulan dan saran merupakan tahapan terakhir yang didapatkan dari analisis dan hasil. Hal ini bertujuan untuk menjawab permasalahan yang telah diidentifikasi. Setelah dilakukan penyimpulan, saran yang diberikan berhubungan dengan pembuatan rute baru untuk setiap kendaraan pengangkutan yang melayani rayon Tangerang Kota, Bumi Serpong Damai, Ciledug, Pamulang, Bintaro, Ciputat, Curug, Cikupa, Balaraja, dan seluruh rumah sakit untuk diberikan kepada PT. Z. 


\section{Pe mbahasan dan Hasil}

\subsection{Data dan Analis is Performansi Perusahaan}

PT. Z merupakan perusahaan swasta distributor produk obat dan barang-barang kebutuhan seharihari yang diproduksi oleh beberapa perusahaan. PT. Z memiliki banyak cabang di Indonesia salah satunya terletak di Tangerang, Banten. PT. Z cabang Tangerang terletak di Jalan Pajajaran Nomor 17 , Tangerang.

PT. Z memiliki jam operasional pada hari Senin hingga Jumat pukul 08.00 - 17.00, sedangkan untuk hari Sabtu 08.00 - 12.00. Konsumen yang dilayani PT. Z adalah toko retail, minimarket, supermarket, apotek, wholesaler, dan rumah sakit di wilayah Tangerang Kota, Bumi Serpong Damai, Ciledug, Pamulang, Bintaro, Ciputat, Curug, Cikupa, Balaraja, dan seluruh rumah sakit. Toko-toko tersebut memiliki jumlah 2.257 outlet.

PT. Z memiliki dua jenis produk yaitu produk obat dan produk kebutuhan sehari-hari. Produk obat merupakan produk kesehatan seperti obat batuk, obat sakit perut, dan lain sebagainya. Sedangkan produk kebutuhan sehari-hari merupakan produk yang digunakan dalam kebutuhan sehari-hari baik makanan ataupun minuman, contohnya seperti Fitbar, Hydrococo, dan lain sebagainya. PT. Z memiliki enam belas kendaraan untuk melakukan pengangkutan barang. Setiap kendaraan dilakukan oleh satu supir dimana sembilan kendaraan digunakan untuk produk kebutuhan seharihari (konsumer) dan tujuh kendaraan digunakan untuk produk obat (pharma). Jenis kendaraan yang digunakan untuk proses distribusi dibagi menjadi dua jenis yaitu L300 dan Grand Max. Pemilihan rute pengiriman ditentukan oleh supir sendiri, sehingga rute pengiriman barang selalu berubah setiap harinya.

Data performansi perusahaan dilihat dari total waktu yang diperlukan supir untuk menyelesaikan pengiriman barang di wilayah Tangerang Kota, Bumi Serpong Damai, Ciledug, Pamulang, Bintaro, Ciputat, Curug, Cikupa, Balaraja, dan seluruh rumah sakit. Pengambilan data dilakukan dengan jarak antar konsumen. Pengambilan data dilakukan dengan ikut langsung pengiriman barang. Data jarak tempuh perjalanan menggunakan satuan kilometer. Pengumpulan data dilakukan pada tanggal 1 Februari untuk wilayah Tangerang Kota, 2 Februari untuk wilayah Bumi Serpong Damai, 3 Februari untuk wilayah Ciledug, 4 Februari untuk wilayah Pamulang, Bintaro, dan Ciputat, 5 Februari untuk wilayah Curug, Cikupa, dan Balaraja, dan 6 Februari untuk seluruh rumah sakit. Berikut merupakan data yang didapat dari hasil pengamatan:

Tabel 3. Waktu Tempuh dan Pelayanan Seluruh Rayon Distribusi

\begin{tabular}{|l|c|c|c|}
\hline \multicolumn{1}{|c|}{ Nama Rayon } & $\begin{array}{c}\text { Total Waktu Tempuh } \\
\text { (menit) }\end{array}$ & $\begin{array}{c}\text { Total Waktu } \\
\text { Pelayanan (menit) }\end{array}$ & $\begin{array}{c}\text { Total Jarak } \\
\text { Pengiriman } \\
\text { (Kilometer) }\end{array}$ \\
\hline Tangerang Kota & 158 & 185 & 120 \\
\hline Bumi Serpong Damai & 165 & 175 & 130 \\
\hline Ciledug & 151,5 & 129 & 113 \\
\hline Pamulang, Bintaro, Ciputat & 130,5 & 119 & 87 \\
\hline Curug, Cikupa, Balaraja & 181,5 & 106 & 121 \\
\hline Seluruh Rumah Sakit & 195 & 156 & 150 \\
\hline
\end{tabular}

Selain melihat total waktu pengiriman pada saat pengamatan, data lain yang didapatkan pada saat melakukan penelitian adalah biaya yang dikeluarkan untuk proses distribusi barang. Data biaya distribusi barang didapatkan langsung dari perusahaan. Databiaya distribusi didapatkan melalui rata-rata biaya distribusi selama bulan Januari dan Februari. Berikut adalah rata-rata biaya distribusi seluruh rayon pengiriman: 
JOURNAL OF INTEGRATED S YSTEM VOL 1. NO. 2, DES EMB ER 2018: 216-229

Tabel 4. Biaya Distribusi Selu ruh Rayon Pengiriman

\begin{tabular}{|c|l|c|c|c|}
\hline \multirow{2}{*}{ Nama Supir } & \multicolumn{2}{|c|}{ Rayon } & \multicolumn{3}{|c|}{ Biaya } \\
\cline { 3 - 5 } & & BBM & Tol & Parkir \\
\hline Ajat & Tangerang Kota & Rp 527.650 & Rp 84.000 & Rp 162.000 \\
\hline Deby & Bumi Serpong Damai & Rp 545.400 & Rp 48.000 & Rp 210.000 \\
\hline H. Fatullah & Ciledug & Rp 515.954 & Rp 30.000 & Rp 138.000 \\
\hline Supriyono & Pamulang, Bintaro, Ciputat & Rp 514.475 & Rp 42.000 & Rp 114.000 \\
\hline Sofiandi & Curug, Cikupa, Balaraja & Rp 528.550 & Rp 54.000 & Rp 138.000 \\
\hline Andi & Seluruh Rumah Sakit & Rp 541.600 & Rp 36.000 & Rp 222.000 \\
\hline
\end{tabular}

Dari data yang telah didapatkan dari hasil pengamatan, maka akan diperoleh total waktu pengiriman untuk satu hari setiap kendaraan. Total waktu pengiriman didaptkan dari penjumlahan waktu persiapan pengiriman, total waktu tempuh,total waktu pelayanan, dan jam istirahat supir.

Tabel 5. Total Waktu Pengiriman Barang dalam Satu Hari Setiap Kendaraan

\begin{tabular}{|c|c|c|c|c|c|c|c|}
\hline \multirow[b]{2}{*}{ No. } & \multirow[b]{2}{*}{ Keterangan } & \multicolumn{6}{|c|}{ Tanggal } \\
\hline & & $\begin{array}{c}\text { Tangerang } \\
\text { Kota }\end{array}$ & $\begin{array}{c}\text { Bumi } \\
\text { Serpong } \\
\text { Damai }\end{array}$ & Ciledug & $\begin{array}{c}\text { Pamulang, } \\
\text { Bintaro, } \\
\text { Ciputat }\end{array}$ & $\begin{array}{l}\text { Curug, } \\
\text { Cikupa, } \\
\text { Balaraja }\end{array}$ & $\begin{array}{c}\text { Seluruh } \\
\text { Rumah } \\
\text { Sakit }\end{array}$ \\
\hline 1 & $\begin{array}{l}\text { Waktu } \\
\text { persiapan } \\
\text { pengiriman }\end{array}$ & 58 & 56 & 53 & 54 & 52 & 50 \\
\hline 2 & $\begin{array}{l}\text { Total waktu } \\
\text { tempuh }\end{array}$ & 158 & 165 & 151,5 & 130,5 & 181,5 & 195 \\
\hline 3 & $\begin{array}{l}\text { Total waktu } \\
\text { pelayanan }\end{array}$ & 185 & 175 & 129 & 119 & 106 & 156 \\
\hline 4 & $\begin{array}{l}\text { Jam istirahat } \\
\text { supir }\end{array}$ & 8 & 10 & 9 & 12 & 8 & 11 \\
\hline \multicolumn{2}{|c|}{ TOTAL (Menit) } & 409 & 406 & 342,5 & 315,5 & 347,5 & 382 \\
\hline \multicolumn{2}{|r|}{ TOTAL (Jam) } & $\begin{array}{c}6 \mathrm{Jam} \\
49 \text { Menit }\end{array}$ & $\begin{array}{c}6 \text { Jam } \\
\text { 46 Menit }\end{array}$ & $\begin{array}{c}5 \text { Jam } \\
42 \text { Menit } \\
30 \text { Detik }\end{array}$ & $\begin{array}{c}5 \text { jam } \\
15 \text { Menit } \\
30 \text { Detik }\end{array}$ & $\begin{array}{c}\text { 6 Jam } \\
\text { 03 Menit } \\
\text { 30 Detik }\end{array}$ & $\begin{array}{c}6 \text { Jam } \\
52 \text { Menit }\end{array}$ \\
\hline
\end{tabular}

\subsection{Pembuatan Rute Distribusi untuk Se tiap Kendaraan Pengangkutan}

Pembuatan rute distribusi menggunakan algoritma Greedy dimana jarak terdekat dari suatu outlet yang diutamakan sehingga diharapkan dapat menghasilkan rute distribusi terpendek. Rute baru yang dibuat menggunakan algoritma Greedy, dimana memilih kota atau tempat tujuan yang belum dikunjungi berdasarkan jarak terdekat dari kota atau tempat sebelumnya. Apabila terdapat jarak yang sama, maka semua kemungkinan rute berdasarkan jarak terpendek dari kota awal menuju kota tujuan akan dilakukan untuk mencari rute yang optimal. Berikut adalah data hasil pembuatan rute baru berdasarkan penerapan langsung:

Tabel 6. Rute Untuk Setiap Kendaraan Pengangkutan

\begin{tabular}{|l|c|c|}
\hline \multicolumn{1}{|c|}{ Nama Rayon } & $\begin{array}{c}\text { Total Waktu Tempuh } \\
\text { (Menit) }\end{array}$ & $\begin{array}{c}\text { Total Jarak Pengiriman } \\
\text { (Kilometer) }\end{array}$ \\
\hline Tangerang Kota & 139 & 93 \\
\hline Bumi Serpong Damai & 139,5 & 93 \\
\hline Ciledug & 108 & 72 \\
\hline Pamulang, Bintaro, Ciputat & 105 & 70 \\
\hline Curug, Cikupa, Balaraja & 159 & 106 \\
\hline Seluruh Rumah Sakit & 151,5 & 101 \\
\hline
\end{tabular}


Rute yang telah dibuat berdasarkan hasil dari perhitungan algoritma Greedy, kemudian dilakukan penerapan langsung pada saat pengiriman barang. Penerapan langsung dilakukan pada 01 Maret 2016 sampai 07 Maret 2016. Berikut adalah hasil penerapan dari masing-masing kendaraan beserta waktu tempuh dan waktu pelayanan:

Tabel 7. Waktu Tempuh dan Pelayanan Seluruh Rayon Rute Distribusi Baru

\begin{tabular}{|l|c|c|c|}
\hline \multicolumn{1}{|c|}{ Nama Rayon } & $\begin{array}{c}\text { Total Waktu Tempuh } \\
\text { (menit) }\end{array}$ & $\begin{array}{c}\text { Total Waktu } \\
\text { Pelayanan (menit) }\end{array}$ & $\begin{array}{c}\text { Total Jarak } \\
\text { Pengiriman } \\
\text { (Kilometer) }\end{array}$ \\
\hline Tangerang Kota & 154 & 185 & 93 \\
\hline Bumi Serpong Damai & 158,5 & 175 & 93 \\
\hline Ciledug & 127,5 & 129 & 72 \\
\hline Pamulang, Bintaro, Ciputat & 117 & 119 & 70 \\
\hline Curug, Cikupa, Balaraja & 170 & 106 & 106 \\
\hline Seluruh Rumah Sakit & 189,5 & 156 & 101 \\
\hline
\end{tabular}

Dari hasil rancangan rute distribusi baru, dapat dihitung ulang total waktu pengiriman dalam satu hari. Berikut adalah total waktu pengiriman untuk setiap kendaraan pengangkutan dengan menggunakan rute distribusi baru:

Tabel 8. Total Waktu Pengiriman Barang dalam Satu Hari Setiap Kendaraan Rute Distribusi Baru

\begin{tabular}{|c|c|c|c|c|c|c|c|}
\hline \multirow[b]{2}{*}{ No. } & \multirow[b]{2}{*}{ Keterangan } & \multicolumn{6}{|c|}{ Tanggal } \\
\hline & & $\begin{array}{c}\text { Tangerang } \\
\text { Kota }\end{array}$ & $\begin{array}{c}\text { Bumi } \\
\text { Serpong } \\
\text { Damai }\end{array}$ & Ciledug & $\begin{array}{c}\text { Pamulang, } \\
\text { Bintaro, } \\
\text { Ciputat }\end{array}$ & $\begin{array}{c}\text { Curug, } \\
\text { Cikupa, } \\
\text { Balaraja }\end{array}$ & $\begin{array}{c}\text { Seluruh } \\
\text { Rumah } \\
\text { Sakit }\end{array}$ \\
\hline 1 & $\begin{array}{l}\text { Waktu } \\
\text { persiapan } \\
\text { pengiriman }\end{array}$ & 55 & 55 & 55 & 55 & 55 & 55 \\
\hline 2 & $\begin{array}{l}\text { Total waktu } \\
\text { tempuh }\end{array}$ & 154 & 158,5 & 127,5 & 117 & 170 & 189,5 \\
\hline 3 & $\begin{array}{l}\text { Total waktu } \\
\text { pelayanan }\end{array}$ & 185 & 175 & 129 & 119 & 106 & 156 \\
\hline 4 & $\begin{array}{l}\text { Jam } \\
\text { istirahat } \\
\text { supir }\end{array}$ & 10 & 10 & 10 & 10 & 10 & 10 \\
\hline \multicolumn{2}{|c|}{ TOTAL (Menit) } & 409 & 406 & 342,5 & 315,5 & 347,5 & 382 \\
\hline \multicolumn{2}{|c|}{ TOTAL (Jam) } & $\begin{array}{l}6 \text { Jam } \\
44 \text { Menit }\end{array}$ & $\begin{array}{c}6 \text { Jam } \\
38 \text { Menit } \\
30 \text { Detik }\end{array}$ & $\begin{array}{c}5 \text { Jam } \\
21 \text { Menit } \\
\text { 30 Detik }\end{array}$ & $\begin{array}{c}5 \text { jam } \\
\text { 01 Menit } \\
\text { 30 Detik } \\
\end{array}$ & $\begin{array}{l}5 \text { Jam } \\
\text { 41 Menit }\end{array}$ & $\begin{array}{c}6 \text { Jam } \\
50 \text { Menit } \\
\text { 30 Detik }\end{array}$ \\
\hline
\end{tabular}

Setelah dilakukan pembuatan rute baru pada tanggal 01 Maret 2016 sampai 07 Maret 2016, maka akan menghasilkan biaya distribusi barang yang baru juga untuk seluruh rayon. Berikut adalah biaya distribusi barang setelah adanya pembuatan rute baru pada bulan Maret untuk seluruh rayon:

Tabel 9. Biaya Distribusi Selu ruh Rayon Pengiriman Rute Distribusi Baru

\begin{tabular}{|c|l|c|c|c|}
\hline \multirow{2}{*}{ Nama Supir } & \multicolumn{2}{|c|}{ Rayon } & \multicolumn{3}{|c|}{ Biaya } \\
\cline { 3 - 5 } & & BBM & Tol & Parkir \\
\hline Ajat & Tangerang Kota & Rp 534.500 & Rp 84.000 & Rp 162.000 \\
\hline Deby & Bumi Serpong Damai & Rp 526.500 & Rp 48.000 & Rp 210.000 \\
\hline H. Fatullah & Ciledug & Rp 543.100 & Rp 30.000 & Rp 138.000 \\
\hline Supriyono & Pamulang, B intaro, Ciputat & Rp 531.300 & Rp 42.000 & Rp 114.000 \\
\hline Sofiandi & Curug, Cikupa, Balaraja & Rp 542.300 & Rp 54.000 & Rp 138.000 \\
\hline Andi & Seluruh Rumah Sakit & Rp 542.100 & Rp 36.000 & Rp 222.000 \\
\hline
\end{tabular}


Berdasarkan penelitian yang telah dilakukan, terdapat perbedaan terhadap total waktu dan jarak pengiriman oleh PT. Z untuk seluruh rayon. Berikut adalah perbandingan total waktu dan jarak pengiriman setiap kendaraan antara rute distribusi lama dengan rute distribusi baru:

Tabel 10. Perbandingan Total Waktu dan Jarak Sebelu m dan Setelah Perbaikan

\begin{tabular}{|l|c|c|c|c|}
\hline \multirow{2}{*}{ Rayon } & \multicolumn{2}{|c|}{ Total Waktu Pengiriman } & \multicolumn{2}{c|}{$\begin{array}{c}\text { Total Jarak Pengiriman } \\
\text { (Kilometer) }\end{array}$} \\
\cline { 2 - 5 } & Sebelum & Setelah & Sebelum & Setelah \\
\hline Tangerang Kota & 6 Jam 49 Menit & 6 Jam 44 Menit & 120 & 93 \\
\hline Bumi Serpong Damai & 6 Jam 46 Menit & $\begin{array}{c}\text { 6 Jam 38 Menit } \\
\text { 30 Detik }\end{array}$ & 130 & 93 \\
\hline Ciledug & $\begin{array}{c}\text { 5 Jam 42 Menit } \\
\text { 30 Detik }\end{array}$ & $\begin{array}{c}\text { 5 Jam 21 Menit } \\
\text { 30 Detik }\end{array}$ & 113 & 72 \\
\hline $\begin{array}{l}\text { Pamulang, Bintaro, } \\
\text { Ciputat }\end{array}$ & $\begin{array}{c}\text { 5 Jam 15 Menit } \\
\text { 30 Detik }\end{array}$ & 5 Jam 01 Menit & 87 & 70 \\
\hline Curug, Cikupa, Balaraja & $\begin{array}{c}\text { 6 Jam 03 Menit } \\
\text { 30 Detik }\end{array}$ & 5 Jam 41 Menit & 121 & 106 \\
\hline Seluruh Rumah Sakit & 6 jam 52 Menit & $\begin{array}{c}\text { 6 jam 50 Menit } \\
\text { 30 Detik }\end{array}$ & 150 & 101 \\
\hline
\end{tabular}

Tabel perbandingan total waktu dan jarak sebelum dan setelah perbaikan diatas, menunjukkan adanya perbedaan total waktu pengiriman dan total jarak pengiriman untuk seluruh rayon pengiriman dalam kota. Pada rayon Tangerang Kota untuk rute baru memiliki waktu 05 menit lebih cepat dibandingkan rute lama dan untuk jarak pengiriman rute baru memiliki jarak 27 kilometer lebih pendek dibandingkan rute lama. Pada rayon Bumi Serpong Damai untuk rute baru memiliki waktu 07 menit 30 detik lebih cepat dibandingkan rute lama dan untuk jarak pengiriman rute baru memiliki jarak 37 kilometer lebih pendek dibandingkan rute lama. Pada rayon Ciledug untuk rute baru memiliki waktu 21 menit lebih cepat dibandingkan rute lama dan untuk jarak pengiriman rute baru memiliki jarak 41 kilometer lebih pendek dibandingkan rute lama. Pada rayon Pamulang, Bintaro, Ciputat untuk rute baru memiliki waktu 14 menit 30 detik lebih cepat dibandingkan rute lama dan untuk jarak pengiriman rute baru memiliki jarak 17 kilometer lebih pendek dibandingkan rute lama. Pada rayon Curug, Cikupa, Balaraja untuk rute baru memiliki waktu 22 menit 30 detik lebih cepat dibandingkan rute lama dan untuk jarak pengiriman rute baru memiliki jarak 15 kilometer lebih pendek dibandingkan rute lama. Pada rayon Seluruh Rumah Sakit untuk rute baru memiliki waktu 01 menit 30 detik lebih cepat dibandingkan rute lama dan untuk jarak pengiriman rute baru memiliki jarak 49 kilometer lebih pendek dibandingkan rute lama.

Perbedaan antara total waktu pengiriman dengan total jarak pengiriman terdapat hal yang perlu diperhatikan yaitu terdapat jarak dimana rute lama dengan rute baru memiliki perbedaan yang tidak terlalu jauh tetapi memliki perbedaan waktu yang cukup jauh antara rute lama dengan rute baru contohnya pada rayon Curug, Cikupa, Balaraja dan sebaliknya terdapat jarak dimana rute lama dengan rute baru memiliki perbedaan yang cukup jauh tetapi memliki perbedaan waktu yang sangat tidak jauh beda antara rute lama dengan rute baru contohnya pada rayon Seluruh Rumah Sakit. Hal ini terjadi dikarenakan tingkat kemacetan disuatu rayon atau daerah berbeda-beda sehingga tidak dapat diprediksi mengenai waktu pengiriman, tetapi dengan adanya perbedaan terhadap jarak pengiriman yang mencapai rata-rata 31 kilometer setiap satu kali pengiriman barang untuk seluruh rayon, maka penggunaan bahan bakar minyak untuk satu kali pengiriman barang akan mengalami pengurangan yang cukup signifikan.

Selain adanya perbedaan terhadap total waktu dan jarak tempuh dalam proses distribusi, terdapat juga perbedaan terhadap biaya distribusi pengiriman barang untuk seluruh outlet PT. Z. Total biaya yang terdapat pada tabel dibawah merupakan penjumlahan dari bahan bakar minyak tol, dan parkir. Berikut adalah perbandingan biaya distribusi barang pada PT. Z untuk seluruh rayon: 
IMPLEMENTAS I ALGORITMA GREEDY (Muhammad Z. U., dkk)

Tabel 11. Perbandingan Biaya Distribusi Sebelum dan Setelah Pembuatan Rute Baru

\begin{tabular}{|c|l|c|c|}
\hline Nama Supir & \multicolumn{1}{|c|}{ Rayon } & $\begin{array}{c}\text { Total Biaya } \\
\text { Sebelum }\end{array}$ & $\begin{array}{c}\text { Total Biaya } \\
\text { Setelah }\end{array}$ \\
\hline Ajat & Tangerang Kota & Rp 773.650 & Rp 780.500 \\
\hline Deby & Bumi Serpong Damai & Rp 799.400 & $\mathrm{Rp} \mathrm{798.400}$ \\
\hline H. Fatullah & Ciledug & Rp 683.954 & Rp 694.500 \\
\hline Supriyono & Pamulang, B intaro, Ciputat & Rp 670.475 & Rp 699.100 \\
\hline Sofiandi & Curug, Cikupa, Balaraja & Rp 720.550 & Rp 723.300 \\
\hline Andi & Seluruh Rumah Sakit & Rp 799.600 & Rp 800.100 \\
\hline
\end{tabular}

Tabel 12. Perbandingan Ju mlah Hari Sebelu m dan Setelah Pembuatan Rute Baru

\begin{tabular}{|c|l|c|c|}
\hline Nama Supir & \multicolumn{1}{|c|}{ Rayon } & $\begin{array}{c}\text { Jumlah Hari } \\
\text { Sebelum/Isi }\end{array}$ & $\begin{array}{c}\text { Jumlah Hari } \\
\text { Setelah/Isi }\end{array}$ \\
\hline Ajat & Tangerang Kota & 3 & 4 \\
\hline Deby & Bumi Serpong Damai & 3 & 4 \\
\hline H. Fatullah & Ciledug & 3 & 4 \\
\hline Supriyono & Pamulang, Bintaro, Ciputat & 4 & 4 \\
\hline Sofiandi & Curug, Cikupa, Balaraja & 3 & 3 \\
\hline Andi & Seluruh Rumah Sakit & 3 & 3 \\
\hline
\end{tabular}

Berdasarkan tabel diatas, terlihat tidak adanya perbandingan terhadap biaya distribusi pengiriman barang pada PT. Z untuk seluruh rayon. Hal ini disebabkan oleh pengisian bahan bakar minyak dilakukan pada saat penelitian. Tetapi terdapat perbedaan waktu pengisian bahan bakar minyak pada pengisian selanjutnya. Dimana pada rayon Tangerang Kota, Bumi Serpong Damai, dan Ciledug yang memiliki sisa bahan bakar minyak yang dapat digunakan untuk 2 hari kedepan sedangkan untuk rayon Pamulang, Bintaro, Ciputat, Curug, Cikupa, Balaraja dan Seluruh Rumah Sakit hanya memiliki perbedaan waktu yang sedikit lebih lama. Perbedaan waktu dan jarak tempuh tersebut menyebabkan pengisian untuk rayon-rayon diatas menjadi lebih lama sehingga dapat mengurangi biaya pendistribusian barang.

Penelitian yang telah dilakukan memperlihatkan bahwa adanya penyebab terjadinya perbedaan total waktu dan jarak tempuh dalam proses distribusi barang pada PT. Z untuk seluruh rayon. Berikut adalah penyebab terjadinya perbedaan total waktu dan jarak tempuh dalam proses distribusi barang pada PT. Z untuk seluruh rayon:

1. Dalam pemilihan outlet yang akan dikunjungi pada rute lama, pemilihan outlet dilakukan oleh supir sendiri. Hal ini menyebabkan waktu pengiriman akan lebih lama dikarenakan supir tidak mengetahui pasti jarak antar outlet.

2. Pada saat pengiriman barang, supir telah mengurutkan outlet mana yang terlebih dahulu didatangi. Tetapi pada saat perjalanan, supir terkadang lupa bahwa outlet tersebut telah terlewati sehingga outlet tersebut menjadi tujuan outlet yang akan datang sehingga jaraknya menjadi lebih jauh.

3. Dalam pemilihan outlet yang akan dikunjungi, supir mempertimbangkan kemacetan pada jamjam tertentu. Sehingga menyebabkan outlet yang seharusnya terdekat dari outlet sebelumnya, tidak didatangi terlebih dahulu.

Selain mengetahui penyebab terjadinya perbedaan total waktu tempuh dan jarak tempuh proses distribusi barang, terdapat kelebihan dan kelemahan dari rute baru. Berikut adalah kelebihan dan kelemahan rute baru pada PT. Z: 
Tabel 13. Kelebihan dan Kelemahan Rute Baru

\begin{tabular}{|c|l|l|}
\hline No. & \multicolumn{1}{|c|}{ Kelebihan Rute Baru } & \multicolumn{1}{c|}{ Kelemahan Rute Baru } \\
\hline 1 & $\begin{array}{l}\text { Total waktu dan jarak tempuh mejadi } \\
\text { lebih pendek atau lebih singkat }\end{array}$ & $\begin{array}{l}\text { Waktu tempuh tidak dapat diprediksi } \\
\text { pada saat penerapan }\end{array}$ \\
\hline 2 & $\begin{array}{l}\text { Biaya distribusi barang menjadi lebih } \\
\text { efisien }\end{array}$ & - \\
\hline
\end{tabular}

\section{Kesimpulan}

Perancangan rute distribusi baru menggunakan algoritma Greedy. Dari hasil rancangan rute distribusi baru dengan algoritma Greedy bahwa hasil yang didapatkan dari algoritma Greedy dengan hasil yang diterapkan langsung memiliki waktu yang berbeda. Hal ini disebabkan oleh faktor kemacetan. Berikut adalah perbandingan waktu tempuh dengan algoritma Greedy dan penerapan langsung.

Tabel 14. Perbandingan Waktu Tempuh Algoritma Greedy dengan Penerapan Langsung

\begin{tabular}{|l|c|c|}
\hline \multirow{2}{*}{ Rayon } & \multicolumn{2}{|c|}{ Waktu Tempuh (menit) } \\
\cline { 2 - 3 } & Algoritma Greedy & Penerapan Langsung \\
\hline Tangerang Kota & 139 & 154 \\
\hline Bumi Serpong Damai & 139,5 & 158,5 \\
\hline Ciledug & 108 & 127,5 \\
\hline Pamulang, Bintaro, Ciputat & 105 & 117 \\
\hline Curug, Cikupa, Balaraja & 159 & 170 \\
\hline Seluruh Rumah Sakit & 151,5 & 189,5 \\
\hline
\end{tabular}

Waktu tempuh antara perhitungan algoritma Greedy dengan penerapan langsung memiliki waktu yang berbeda, namun terdapat peningkatan atau efiensi waktu dan jarak sebelum dan setelah adanya perbaikan rute. Rata-rata perbedaan rute baru dengan rute lama dengan total waktu pengiriman untuk seluruh rayon adalah 12 menit sedangkan rata-rata perbedaan total jarak pengiriman untuk seluruh rayon adalah 31 Kilometer.

Selain adanya perbedaan waktu dan jarak pada sebelum dan setelah adanya perbaikan rute, perbedaan lainnya terdapat pada biaya distribusi. Terdapat perbedaan biaya dimana setelah adanya perbaikan rute menjadi lebih besar dibandingkan sebelum adanya perbaikan rute, hal itu disebabkan oleh banyaknya bahan bakar minyak pada saat mengisi. Sehingga perbedaan biaya dapat disambungkan dengan pengisian bahan bakar minyak. Dimana pada rayon Tangerang Kota, Bumi Serpong Damai, dan Ciledug yang memiliki sisa bahan bakar minyak yang dapat digunakan untuk 2 hari kedepan sedangkan untuk rayon Pamulang, Bintaro, Ciputat, Curug, Cikupa, Balaraja dan Seluruh Rumah Sakit hanya terdapat perbedaan waktu pengisian bahan bakar bensin yang menjadi lebih lama. Sehingga dapat dis impulkan bahwa pembuatan rute baru dengan menggunakan algoritma Greedy dalam menyelesaikan permasalahan distribusi dapat mempersingkat atau dapat membuat lebih optimal, hal ini terlihat dari perbedaan waktu dan jarak pengiriman sebelum dan setelah adanya pembuatan rute baru serta terdapatnya perbedaan jumlah hari yang dalam penggunaan bahan bakar minyak.

\section{Saran}

Saran-saran yang dapat diberikan untuk pene litian berikutnya adalah sebagai berikut:

1. Perhitungan rute baru dengan menggunakan Travelling Salesman Problem algoritma Greedy memiliki kekurangan pada saat memasukkan database jarak yang perhitungan jaraknya mengalami pembulatan. Sehingga hasil yang didapatkan kurang valid.

2. Perancangan rute dengan menggunakan TSP akan lebih baik apabila mempertimbangkan variabel lain agar yang diterapkan dengan yang diperhitungkan dapat lebih valid dan dapat diterapkan di kenyataan. 


\section{Daftar Pustaka}

Andri, Suyandi, Win, W. (2013), Aplikasi Travelling Salesman Problem Dengan Metode Artificial Bee Colony, JSM STMIK Mikroskil, Nomor 1, Volume 14.

Applegate, D. L., Bixby, R. E., Chvatal, V dan Cook, W. J. (2006), The Travelling Salesman Problem: A Computational Study, Princeton University Press, New Jersey.

Budiarto, T. (1993). Dasar Pemasaran. Universitas Gunadarma, Yogjakarta.

Kusrini, Istiyanto, J. E. (2007), Penyelesaian Travelling Salesman Problem Dengan Algoritma Cheapest Insertion Heuristics dan Basis Data, Jurnal Informatika, Nomor 2, Volume 8.

Mindaputra, E. (2009), Penggunaan Algoritma Ant Colony System dalam Travelling Salesman Problem (TSP) pada PT. Eka Jaya Motor, Tugas Sarjana Fakultas Sains dan Matematika. Universitas Diponegoro, Semarang.

Nasution, A. H. (2006), Manajemen Industri, Penerbit Andi, Yogjakarta.

Taha, H. A. (2007), Operations Research An Introduction Edisi 8, Pearson Prentice Hall, New Jersey.

Wijayanti, D. T. (2013), Algoritma Optimasi Untuk Penyelesaian Travelling Salesman Problem, Jurnal Transformatika, Nomor 1, Volume 11, halaman: 1-6.

Zarlis, M. dan Handrizal. (2008), Algoritma dan Pemrograman: Teori dan Praktik Dalam Pascal Edisi Kedua, USU Press, Medan. 